\title{
Article
}

\section{Two of a Kind? Mapping the Psychopathological Space between Obesity with and without Binge Eating Disorder}

\author{
Laura Marie Sommer ${ }^{1,+}$, Georg Halbeisen ${ }^{2}(D)$, Yesim Erim ${ }^{1}$ and Georgios Paslakis ${ }^{2, *}$ \\ 1 Department of Psychosomatic Medicine and Psychotherapy, University Hospital of Erlangen, \\ Friedrich-Alexander-University Erlangen-Nürnberg (FAU), 91054 Erlangen, Germany; \\ laura.marie.sommer@outlook.de (L.M.S.); yesim.erim@uk-erlangen.de (Y.E.) \\ 2 University Clinic for Psychosomatic Medicine and Psychotherapy, Medical Faculty, Campus East-Westfalia, \\ Ruhr-University Bochum, Virchowstr. 65, 32312 Luebbecke, Germany; georg.halbeisen@rub.de \\ * Correspondence: georgios.paslakis@rub.de \\ + The present work was performed by L.M.S. in fulfillment of the requirements for obtaining the degree \\ "Dr. Med.".
}

\section{check for} updates

Citation: Sommer, L.M. Halbeisen, G.; Erim, Y.; Paslakis, G. Two of a Kind? Mapping the Psychopathological Space between Obesity with and without Binge Eating Disorder. Nutrients 2021, 13, 3813. https://doi.org/10.3390/ nu13113813

\section{Academic Editors:}

Fernando Fernandez-Aranda, Janet Treasure and Empar Lurbe

Received: 10 October 2021

Accepted: 24 October 2021

Published: 26 October 2021

Publisher's Note: MDPI stays neutral with regard to jurisdictional claims in published maps and institutional affiliations.

Copyright: (c) 2021 by the authors. Licensee MDPI, Basel, Switzerland. This article is an open access article distributed under the terms and conditions of the Creative Commons Attribution (CC BY) license (https:// creativecommons.org/licenses/by/ $4.0 /)$.

\begin{abstract}
Background: Obesity (OB) is a frequent co-morbidity in Binge Eating Disorder (BED), suggesting that both conditions share phenotypical features along a spectrum of eating-related behaviors. However, the evidence is inconsistent. This study aimed to comprehensively compare OB-BED patients against $\mathrm{OB}$ individuals without BED and healthy, normal-weight controls in general psychopathological features, eating-related phenotypes, and early life experiences. (2) Methods: OB-BED patients $(n=37), \mathrm{OB}$ individuals $(n=50)$, and controls $(n=44)$ completed a battery of standardized questionnaires. Responses were analyzed using univariate comparisons and dimensionality reduction techniques (linear discriminant analysis, LDA). (3) Results: OB-BED patients showed the highest scores across assessments (e.g., depression, emotional and stress eating, food cravings, food addiction). OB-BED patients did not differ from $\mathrm{OB}$ individuals in terms of childhood traumatization or attachment styles. The LDA revealed a two-dimensional solution that distinguished controls from OB and OB-BED in terms of increasing problematic eating behaviors and attitudes, depression, and childhood adversities, as well as OB-BED from OB groups in terms of emotional eating tendencies and self-regulation impairments. (4) Conclusions: Findings support the idea of a shared spectrum of eating-related disorders but also highlight important distinctions relevant to identifying and treating BED in obese patients.
\end{abstract}

Keywords: binge eating disorder; obesity; food addiction; impulsivity; emotional eating; childhood trauma questionnaire; psychotherapy

\section{Introduction}

Binge Eating Disorder (BED) is the most common eating disorder (ED) in western countries, with lifetime prevalence averaging 1.57\% [1]. In recognition of this growing prevalence, BED was included in the 5th edition of the Diagnostic and Statistical Manual of Mental Disorders (DSM-5) [2]. According to DSM-5 criteria, BED patients suffer from reoccurring binge eating episodes of ingesting large amounts of food in a short period of time, with associated loss of control over their food intake. Negative feelings such as shame or guilt accompany these episodes. The severity of the disorder depends on the frequency of binge eating episodes per week, with thresholds demarcating mild, moderate, severe, and extreme BED.

Obesity is a frequent co-morbidity in BED due to the high volume of food intake and lack of compensatory behaviors in BED patients [3]. In the German general population, $25.9 \%$ of men and $24.4 \%$ of women are considered obese by a body mass index $(\mathrm{BMI})>30 \mathrm{~kg} / \mathrm{m}^{2}$ [4]. Among individuals with BED symptoms, however, $41.7 \%$ are obese, compared with only $15.8 \%$ of individuals with no history of an ED [5]. Comorbid obesity in 
BED patients is a major cause for concern, as obesity is associated with a wide range of physical afflictions, including cardiovascular diseases, type II diabetes, and several cancers [6], as well as with increased psychological burden, such as depression, low self-esteem, body image disturbances, perceived stress, and lowered quality of life [7].

The frequent co-morbidity of BED and obesity may suggest that both conditions are part of a broad spectrum of eating-related behaviors, implying that patients could transition from one condition to another [8]. This idea is consistent with recent studies linking obesity with comorbid BED and obesity without BED to shared phenotypical, in part clinical, features. For example, early life adversities such as trauma have been associated with the development of both BED and obesity $[9,10]$, possibly due to lasting impairments in coping mechanisms and metabolic alterations due to stress [11,12]. In a similar vein, insecure attachment styles that develop in early childhood have been associated with emotional eating, eating unhealthy food, and binge eating [13], which studies link to the pathogenesis of BED and obesity [14,15]. Neurobiological studies also show that dopaminergic and glutamatergic pathways play a crucial role in developing and maintaining both conditions [16], further corroborating the idea of a shared continuum between obesity with comorbid BED and obesity without BED.

Patients with BED and comorbid obesity also differ from obese individuals without BED regarding a variety of phenotypical features. Patients with BED and obesity display higher levels of impulsivity than obese individuals without BED, in general, and especially toward food cues $[17,18]$. Neurobiological studies have shown that BED patients with obesity show lower activity levels in brain areas responsible for control and self-regulatory processes than obese individuals without BED [17]. Patients with BED have lower response inhibition abilities when presented with food cues in a go-no-go task, a finding associated with decreased activation of the prefrontal control network, which is active during successful no-go (withhold) trials in non-BED obese individuals [19]. Evidence also suggests a more compromised hormonal regulation of hunger and satiety in BED compared to obesity, for example, as mirrored in findings of blunted postprandial ghrelin suppression in BED compared with obesity [20]. In addition, Schulz and Laessle [21] found that depression weakens self-regulation in obese BED patients but not in obese individuals without BED, suggesting a possible link between depression and binge eating behavior. Finally, a recent study from our group showned that negative mood was associated with decreased food avoidance in obese BED patients only, but not in obese individuals without BED [22].

The evidence is less consistent on commonalities and disparities between obese patients with comorbid BED and obese individuals without BED concerning eating-related symptomatology other than binge eating. Strong concerns about shape and weight are core features BED shares with other EDs like anorexia nervosa or bulimia nervosa [23,24], and significant concerns of shape and weight also emerge in connection with obesity without BED in large community samples [25]. Similarly, several eating styles have been associated with obesity and comorbid BED in comparison with obesity without BED, such as emotional eating [22,26-30], eating in response to stress [31], and lower success in dieting and restraint [32], although especially research on the role of restraint has generated inhomogeneous results $[33,34]$. Newer concepts such as food craving and the strong desire to eat certain foods show stronger correlations with binge eating than obesity [35-37]. Food addiction, which among others, describes a loss of control over eating, cravings, and continued excessive food consumption contrary to the knowledge of adverse consequences [38], is also associated with a higher frequency of binge episodes and emotional eating $[39,40]$. At the same time, food addiction may play a role in obesity, too [41].

Further exploration of the commonalities and disparities between obesity with comorbid BED and obesity without BED is warranted, considering the results may help identify specific targets of prevention and intervention. Existing therapeutic approaches and weight loss strategies for obesity, such as dietary programs or physical exercise, are often unsuccessful or do not lead to enduring weight reductions [7,42]. Obese patients with BED also exhibit smaller weight reductions compared with obese individuals without an 
ED following weight-loss surgery [43,44]. Cognitive behavioral therapy (CBT), which functions as the foundation of BED treatment, aims to modify eating behaviors and has been found to lead to a remission of binge episodes among $64.4 \%$ of patients, including positive effects in terms of co-occurring psychological impairments [32,45]. However, the evidence for long-term results after cessation of CBT is still disappointing [32,46], suggesting BED treatment needs further improvement.

Thus far, the commonalities and differences in phenotypical features between obese BED patients and obese individuals without BED have been mapped across a range of studies but are seldom explored within a single investigation. One cannot exclude that differences in study design or sample composition account for some inconsistencies across findings, suggesting the need for a more comprehensive investigation. A comprehensive investigation also allows for the assessment the relative contribution of different sets of phenotypical and clinical features in grouping and distinguishing obese patients with BED from obese individuals without BED, aiding in theory development and prognostic application. Here, we conducted an exploratory study in which we assessed eatingrelated symptomatology (shape and weight concerns [23,24], emotional eating [26-30,47], dieting [32], food craving [37], and food addiction [48]), general psychopathology (impulse control impairments [17], depression [34]), and early life experiences (childhood traumatic events $[9,10]$, attachment styles $[14,15])$ using standardized questionnaires. Specifically, we aimed to comprehensively compare obese patients with BED against obese individuals without BED as well as healthy, normal-weight controls in terms of these features, using univariate analyses and dimensionality reduction techniques.

\section{Materials and Methods}

\subsection{Participants}

A total of 131 German-speaking adults ( 90 women, 41 men, mean age $=42.7$ years, age range: 21 to 82 years) participated in the study: $n=37$ obese patients with an active BED (OB-BED; BMI $\left.>30 \mathrm{~kg} / \mathrm{m}^{2}\right), n=50$ weight-matched obese controls (OB; BMI $>30 \mathrm{~kg} / \mathrm{m}^{2}$ ), and $n=44$ healthy, normal-weight controls with a BMI between 19.0 and $24.9 \mathrm{~kg} / \mathrm{m}^{2}$ (CO). OB-BED patients were recruited from the psychosomatic ward and day clinic of the Department for Psychosomatic Medicine and Psychotherapy at the University Hospital of Erlangen. Patients were both newly diagnosed individuals as well as individuals who had already received eating disorder-specific treatment in the past. University students, hospital employees, and individuals considering bariatric surgery as an option for weight loss were recruited for the OB and CO groups. For the diagnosis of BED, DSM-5 criteria (e.g., recurrent episodes of binge eating, marked distress, absence of compensatory behaviors) had to be fulfilled [2], which were assessed and confirmed by a physician with longstanding experience in diagnosing and treating eating disorders, in addition to the review of preexisting documentation and the use of a clinical questionnaire [49]. Common inclusion criteria across groups were: 18 years or older, absence of acute severe psychiatric or somatic concomitant diseases, and no acute suicidal tendencies. ED diagnoses other than BED, or other clinically relevant ED symptoms, served as exclusion criteria; these exclusion criteria were verified before study inclusion during a clinical interview by the physician in charge.

The study was carried out in accordance with the Declaration of Helsinki and was reviewed and approved by the local ethics committee of the Friedrich-Alexander-University Erlangen-Nürnberg (approval no.: 267_17B, 4 December 2017). A sample size of $N \geq 130$ was targeted to achieve a power of 0.70 for detecting medium- or larger-sized (i.e., $f \geq 0.25$ ) group differences at $p \leq 0.05$ [50]. Participants had no previous experience with the procedure, provided informed, written, and signed consent, and were randomly sampled by convenience among local individuals and patients that were or became available during the recruitment period. Refusals to participate were not recorded; thus, information on participation rate cannot be provided. 


\subsection{Procedure}

All participants completed a battery of paper-and-pencil questionnaires at their own pace, detailed below, to measure different aspects of eating-related symptomatology, general psychopathology, and childhood adversities.

\subsection{Assessment of Eating-Related Symptomatology}

Problematic eating behaviors and attitudes, such as shape and weight concerns, were assessed using the Eating Disorder Examination-Questionnaire (EDE-Q). The EDE-Q [51] is a self-report questionnaire modeled after the Eating Disorder Examination [52]. It is composed of 22 items and assesses four subcategories: Restraint, Eating Concern, Weight Concern, and Shape Concern. Items are rated on a 6-point scale, based on how often the eating disorder characteristics occurred within the past 28 days. Mean scores are computed for each subcategory, as well as for the overall questionnaire [53].

Emotional eating tendencies were assessed using the Salzburger Emotional Eating Scale (SEES) [54]. The SEES contains twenty items, scored on a 5-point Likert scale and grouped into four subcategories for effects of emotions on eating (happiness, sadness, anger, and anxiety), each yielding a mean score. Mean scores higher than 3 suggest an increased influence of emotion on food intake, while scores below 3 suggest a decreased influence of emotion on food intake.

The Salzburger Stress Eating Scale (SSES) [31] is a ten-item questionnaire that measures general stress eating tendencies, which we included because stress can affect eating even after controlling for the effects of negative emotions [55]. Each item is scored on a 5-point Likert scale ranging from $1=\mathrm{I}$ eat much less than usual to $5=\mathrm{I}$ eat much more than usual. A mean score is calculated using all items. Mean scores higher, or lower, than 3 indicate an increased, or decreased, intake when the individual feels stressed, respectively.

As further measures of emotional eating and restraint, we included the Dutch Eating Behavior Questionnaire (DEBQ) [56]. The scale also measures external eating, the tendency to eat after being exposed to food cues. The Emotional Eating scale further splits into effects of diffuse emotions and clearly labeled emotions. The German version has 30 items that are scored on a 5-point Likert Scale [57].

As an additional measure of restraint eating, we included the Perceived Self-Regulatory Success in Dieting (PSRS) [58], a short questionnaire that can be used for distinguishing between successful and unsuccessful dieters [59]. Three brief questions are used to assess whether respondents find it easy to watch their weight, lose weight, or find it challenging to stay in shape. The items are scored on a 7-point Likert scale, with the last item being reversed coded.

Food craving was assessed with the Food Craving Questionnaire-Trait (FCQ-T) [60]. It consists of 39 items scored on a 6-point Likert scale, which in the German version [35] are separated into six subscales: Intentions/Lack of control, Reinforcement, Thoughts/Guilt, Emotions, Cues, and Hunger.

Finally, we also included the Yale Food Addiction Scale (YFAS) 2.0 [61] in order to measure addiction-like eating behavior. The YFAS 2.0 has 35 items which assess how many of the eleven symptoms of food addiction according to DSM-5 addiction criteria (amount, attempts to quit, time, reduced activities, consequences, tolerance, withdrawal, craving, failed obligations, problems, hazardous situations) are present, as well as if the eating behavior causes impairment or distress. The items are scored on a 7-point scale, with each symptom having a specific threshold score. According to the number of symptoms present, the severity of food addiction is considered to be mild (2-3), moderate (4-5), or severe (7 or more symptoms). The endorsement of impairment/distress is necessary for diagnosing addiction at all [62].

\subsection{Assessment of General Psychopathology}

The Barratt Impulsiveness Scale-Short Version (BIS-15) [63] was used to measure participants' impulsiveness utilizing a three-factor model: non-planning impulsivity, motor 
impulsivity, and attentional impulsivity. The BIS-15 contains 15 items, each scored on a 4-point Likert scale with six items scored inversely. Accordingly, a sum score of all items ranges between 15 and 60 .

The Beck Depression Inventory (BDI-II) [64] was additionally included as a widely used self-report inventory for measuring the severity of depression in adults. The BDI-II contains 21 items, each scored on a 4-point Likert scale, with sum scores ranging between 0 and 63.

\subsection{Assessment of Early Life Experiences}

Two questionnaires on early life experiences were also included. The short version of the Childhood Trauma Questionnaire (CTQ) [65] contains 28 items and screens for five types of childhood trauma, including physical, sexual, and emotional abuse, as well as physical and emotional neglect. Each subcategory contains five items, and the remaining three items comprise the Minimization/Denial validity scale, which indicates underreporting of maltreatment. All items are rated on a 5-point Likert scale, with some items scored inversely, yielding a sum score for each subcategory.

Finally, the redesigned German version of the Relationship Scales Questionnaire (RSQ) [66] was used to assess attachment style and distinguished between "Separation anxiety", "Closeness anxiety", "Lack of trust," and "Wish to be independent". Each of the 30 items are ranked on a 5-point Likert scale, yielding a mean score for each subcategory of attachment.

\subsection{Data Aggregation and Analysis}

Participant responses were aggregated according to each questionnaire's specifications. For questionnaire total scores, univariate analyses of variance (ANOVAs) were conducted to assess differences between groups (OB-BED vs. OB vs. CO). To account for multicollinearity among questionnaire subscales, between-group differences on subscales were analyzed using one-way multivariate analysis of variance (MANOVAs). Anthropometric variables (age, BMI) were compared between groups using one-way ANOVA, and a Chi-squared test of independence (for sex ratio), with group as the independent variable. Chi-square tests were also used to analyze symptom severity in the YFAS 2.0.

For assessing the relative contribution of different sets of features in grouping and distinguishing OB-BED patients from $\mathrm{OB}$ and $\mathrm{CO}$ individuals, a linear discriminant analysis (LDA) was conducted with participant group as the criterion variable and questionnaire scores as predictor variables. The LDA's primary goal is to identify along how many and which dimensions (i.e., the discriminant functions) the participant groups can be distinguished from each other based on a set of predictor variables. Correlations (loadings) between predictors and discriminant functions can be used to indicate the relative value of each questionnaire to the discriminant function. Prior probabilities were adjusted to control for unequal group sizes. Box's $M$ statistic was used to test for violations of the assumption of equal covariance matrices.

The significance level for all analyses was set at $p \leq 0.05$. Effect sizes are reported as $\eta^{2}$. Post hoc pairwise comparisons report Bonferroni-adjusted $p$-values for multiple comparisons. Variable values are reported as mean \pm standard deviation. Z-standardized values of questionnaires are depicted in Figure 1. Unstandardized means \pm standard deviation for questionnaire responses are summarized in Appendix A (Table A1). All data were analyzed with the Statistical Package for the Social Sciences (SPSS 25; IBM Corp., Armonk, NY, USA). 


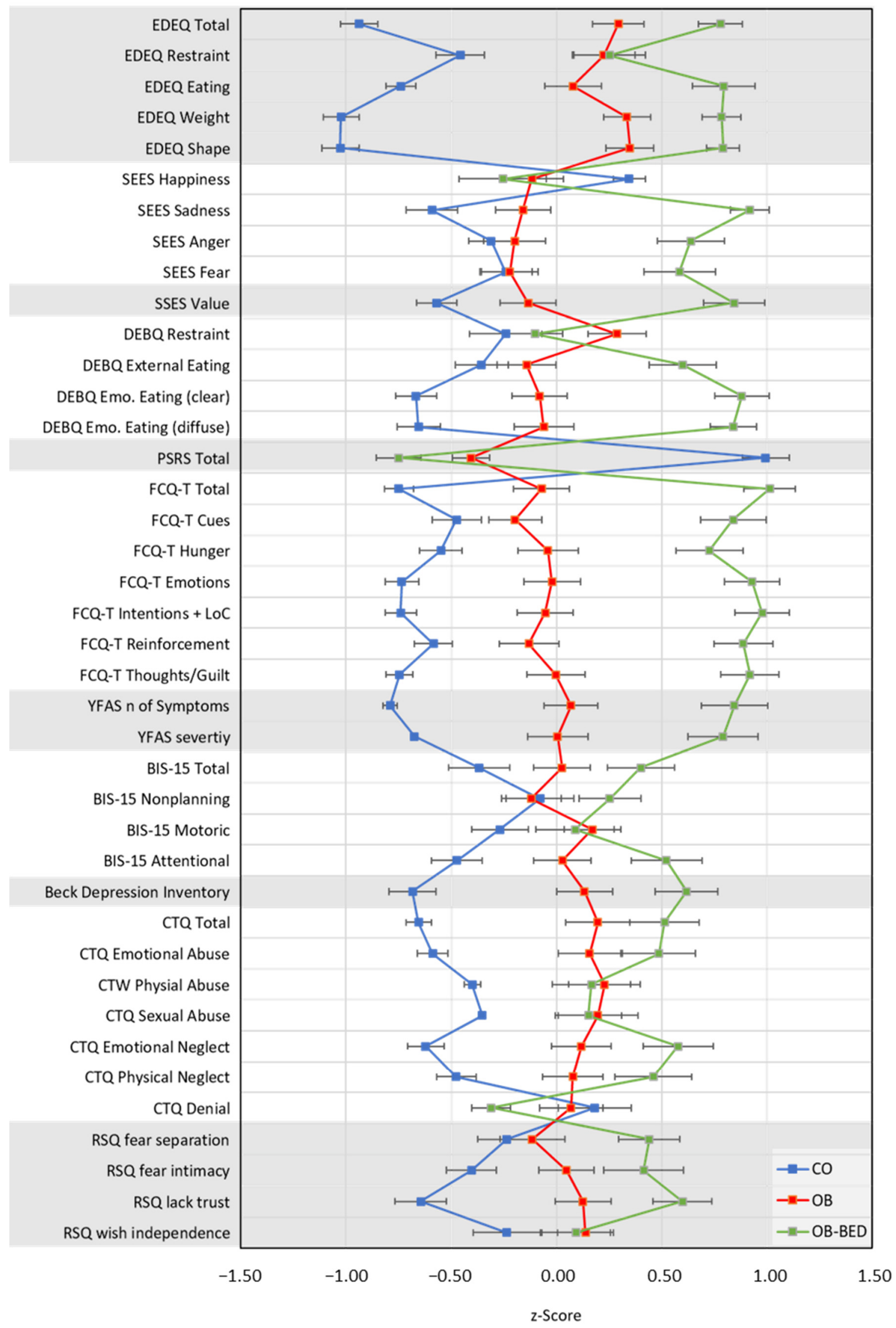

Figure 1. Mean questionnaire scores (z-standardized) and standard errors for the examined groups. $\mathrm{CO}=\mathrm{control}$; $\mathrm{OB}=$ obese; $\mathrm{OB}-\mathrm{BED}=$ obese with co-morbid Binge Eating Disorder. 


\section{Results}

\subsection{Participant Demographics}

Participant demographics are summarized in Table 1. Participant sexes were similarly distributed across participant groups, $\chi^{2}(\mathrm{df}=2)=0.49, p=0.78$. Groups differed as intended in terms of BMI (post hoc: OB-BED $=\mathrm{OB}>\mathrm{CO}$ ), $F(2,128)=125.05, p<0.001$, $\eta^{2}=0.66$, and were similar in age, $F(2,128)=3.02, p>0.05$.

Table 1. Demographic information as a function of participant group.

\begin{tabular}{cccc}
\hline Variable & CO & OB & OB-BED \\
\hline$n(\mathrm{~m}, \mathrm{f})$ & 14,30 & 17,33 & 10,27 \\
age & $41.7 \pm 16.8$ & $46.1 \pm 10.7$ & $39.3 \pm 11.2$ \\
BMI $\left(\mathrm{kg} / \mathrm{m}^{2}\right)$ & $22.5 \pm 1.6$ & $42.9 \pm 9.1$ & $46.3 \pm 9.3$ \\
\hline
\end{tabular}

$\bar{n}=$ number of participants; $\mathrm{m}=$ male; $\mathrm{f}=$ female; $\mathrm{BMI}=$ body mass index; $\mathrm{CO}=$ control; $\mathrm{OB}=$ obese; $\mathrm{OB}-\mathrm{BED}=$ obese with co-morbid Binge Eating Disorder. Values report mean \pm standard deviation.

\subsection{Eating-Related Symptomatology: EDEQ, SSES, SEES, DEBQ, PSRS, FCTQ, \& YFAS 2.0}

EDE-Q total scores of disordered eating varied significantly between groups, $F(2,125)=62.82, p<0.001, \eta^{2}=0.50$, with OB-BED scoring higher than OB and CO, $p s<0.008$, and $\mathrm{OB}$ scoring higher than $\mathrm{CO}, p<0.001$. Expectedly, the analysis of subcategory scores replicated the effect, $F(8,244)=20.88, p<0.001, \eta^{2}=0.27$, Wilk's $\Lambda=0.41$, with OB-BED and OB showing higher scores than CO on Restraint, Eating Concern, Weight Concern, and Shape Concern scales, $p s<0.002$. With the exception of restraint, $p=1.00$, OB-BED also scored consistently higher than $\mathrm{OB}, p \mathrm{~s}<0.007$.

Emotional eating according to SEES subscales varied by group, $F(8,250)=9.23$, $p<0.001, \eta^{2}=0.23$, Wilk's $\Lambda=0.60$, with OB-BED scoring lower on the happiness subcategory than $\mathrm{CO}, p=0.02$, but not $\mathrm{OB}, p=1.00$. OB-BED scored higher on the sadness, anger, and fear subcategories than both $\mathrm{OB}$ and $\mathrm{CO}, p \mathrm{~s}<0.001$. With the exception of higher sadness scores for $\mathrm{OB}$ than $\mathrm{CO}, p=0.03, \mathrm{OB}$ and $\mathrm{CO}$ were not significantly different, ps $>0.07$.

SSES mean scores for general stress eating tendencies also differed significantly between groups, $F(2,127)=29.77, p<0.001, \eta^{2}=0.32$, with $\mathrm{CO}$ scoring lower than $\mathrm{OB}$, $p=0.04$, and OB-BED, $p<0.001$, and OB scoring lower than OB-BED, $p<0.001$.

On the DEBQ, scores differed between groups across restraint, external eating and emotional eating subscales, $F(8,246)=11.31, p<0.001, \eta^{2}=0.27$, Wilk's $\Lambda=0.53$. CO scored significantly lower on restraint eating behaviors than $\mathrm{OB}, p=0.03$, but not lower than OB-BED, $p=1.00$, with OB and OB-BED remaining comparable, $p=0.21$. On the external eating subscale, OB-BED scored higher than $\mathrm{OB}$ and $\mathrm{CO}, p s<0.001$, with $\mathrm{OB}$ and $\mathrm{CO}$ remaining comparable, $p=0.82$. Finally, on both subscales of emotional eating, OB-BED scored higher than $\mathrm{OB}$ and $\mathrm{CO}, p \mathrm{~s}<0.001$, and $\mathrm{OB}$ scored higher than $\mathrm{CO}, p \mathrm{~s}<0.002$.

In terms of the PSRS perceived success in dieting scores, group differences were obtained, $F(2,120)=80.71, p<0.001, \eta^{2}=0.57$, due to CO scoring significantly higher than both OB and OB-BED groups, $p s<.001$. OB and OB-BED did not differ in terms of PSRS, $p=0.07$.

FCTQ food craving total scores differed significantly between groups, $F(2,121)=58.02, p<0.001, \eta^{2}=0.49$, with OB-BED scoring higher than OB and CO, $p s<0.001$, and $\mathrm{OB}$ scoring higher than $\mathrm{CO}, p<0.001$. This pattern reproduced consistently across FCTQ subscales (OB-BED $>$ OB $>C O, p s<0.001), F(12,232)=9.10, p<0.001$, $\eta^{2}=0.32$, Wilk's $\Lambda=0.46$, with the exception of the food-cue elicited craving, which did not differ between $\mathrm{OB}$ and $\mathrm{CO}, p=0.38$.

Finally, food addiction symptoms based on the YFAS 2.0 differed significantly across groups, $F(2,128)=45.66, p<0.001, \eta^{2}=0.42$, with OB-BED scoring higher than $\mathrm{OB}$ and $\mathrm{CO}$, $p s<0.001$, and $\mathrm{OB}$ scoring higher than $\mathrm{CO}, p<0.001$. A Chi-squared test of independence revealed that groups also differed in terms of the clinical significance of food addiction symptoms, $\chi^{2}(\mathrm{df}=2)=49.97, p<0.001$, with $0 \%$ of $\mathrm{CO}, 40 \%$ of $\mathrm{OB}$ and $76 \%$ of OB-BED 
indicating clinically significant impairments. However, of those classified as severe food addicted $(n=31), 61 \%$ were in the OB-BED group and $39 \%$ were in the OB group, which did not significantly differ from the expected values based on sample size distribution, $p=0.67$.

\subsection{General Psychopathology: BIS-15 \& BDI}

BIS-15 total impulsivity scores differed significantly between groups, $F(2,128)=6.48$, $p<0.002, \eta^{2}=0.09$, with OB-BED scoring higher than CO, $p<0.001$, whereas OB-BED and $\mathrm{OB}$, and $\mathrm{OB}$ and $\mathrm{CO}$ remained comparable, $p \mathrm{~s}>0.14$. Subscale analysis, $F(6,252)=4.56$, $p<0.001, \eta^{2}=0.10$, Wilk's $\Lambda=0.81$, revealed that overall differences were due to OB-BED scoring higher on attentional impulsivity than $\mathrm{OB}$ and $\mathrm{CO}, p \mathrm{~s}<0.05$, and $\mathrm{OB}$ scoring higher than $\mathrm{CO}, p=0.03$. All groups remained comparable on non-planning impulsivity and motor impulsivity subscales, $p \mathrm{~s}>0.10$.

On the BDI depression inventory, OB-BED scored higher than $\mathrm{OB}$ and $\mathrm{CO}, p \mathrm{~s}<0.04$, and OB scored higher than CO, $p<0.001, F(2,126)=23.78, p<0.001, \eta^{2}=0.27$.

\subsection{Early Life Experiences: $C T Q \mathcal{E} R S Q$}

CTQ total scores for childhood trauma revealed significant groups differences, $F(2,128)=19.67, p<0.001, \eta^{2}=0.24$, with CO scoring lower than both OB-BED and $\mathrm{OB}, p \mathrm{~s}<0.001$, and similar scores for OB-BED and $\mathrm{OB}, p=0.30$. In terms of trauma subcategories, group differences were also significant, $F(10,248)=4.51, p<0.001, \eta^{2}=0.15$, Wilk's $\Lambda=0.72$, with CO scoring lower than OB-BED and OB in all categories, $p \mathrm{~s}<0.03$, except for OB-BED in terms of sexual abuse, $p=0.06$. OB-BED and OB did not significantly differ in any of the subcategories, $p s>0.05$. Denial scores indicating underreporting did not differ between groups, $F(2,128)=2.70, p=0.07$.

Attachment styles according to RSQ scores differed between groups, $F(8,244)=6.32$, $p<0.001, \eta^{2}=0.17$, Wilk's $\Lambda=0.69$, with differences found on separation anxiety, closeness anxiety, and lack of trust subscales. For separation anxiety, OB-BED revealed elevated scores compared to $\mathrm{OB}$ and $\mathrm{CO}$ groups, $p s<0.03$, which themselves remained comparable, $p=1.00$. Closeness anxiety was only elevated for OB-BED when compared to CO, $p<0.001$, whereas all other comparisons were not significant, $p s>0.15$. Finally, all groups differed in lack of trust, $p s<0.05$, with OB-BED scoring higher than $\mathrm{OB}$ and $\mathrm{CO}$, and $\mathrm{OB}$ scoring higher than $\mathrm{CO}$. There were no significant differences on the wish to be independent subscale, ps $>0.25$.

\subsection{Discriminant Analysis}

Given that in almost all questionnaires and subcategories, significant differences were found between OB-BED, OB and CO groups, a linear discriminant analysis (LDA) was conducted to assess the relative contribution of different sets of psychopathological features in grouping and distinguishing the groups. Given the high internal consistencies of SEES (with happiness reverse-coded), DEBQ, and RSQ subscales (excluding wish for independence, which did not differ between groups), Cronbach's $\alpha 0.74,0.71$, and 0.66, respectively, mean total scores for these questionnaires were computed. Thus, eleven total scores for all questionnaires were entered as predictors in the LDA. Because of missing scores on at least one questionnaire, 116 cases were included in the analysis.

Results of the LDA revealed a two-dimensional solution (see Figure 2), with a significant function 1 accounting for $89.6 \%$ of the variance, $\chi^{2}(22)=174.84, p<0.001$, and a significant function 2 accounting for the remaining $10.4 \%$ of variance, $\chi^{2}(10)=30.49$, $p<0.001$. Group centroids (i.e., means in multivariate space) suggest a clear distinction between $\mathrm{CO}(-2.17), \mathrm{OB}(0.69)$ and OB-BED (1.80) groups due to predictors associated with function 1 , with predictors related to function 2 primarily distinguishing between OB $(-0.68)$ and OB-BED (0.68) groups, with CO (0.21) in between. In order of importance, predictors primarily associated with function 1 (loadings in parentheses) were EDEQ $(0.70)$, PSRS (-0.69), YFAS (0.49), BDI (0.41), CTQ (0.36), and RSQ (0.34). Function 2 predic- 
tors were FCTQ (0.71), SSES (0.64), SEES (0.63), DEBQ (0.45), and BIS-15 (0.24). Because Box's $M$ statistic indicated a significant violation of the assumption of equal covariance at $p<0.001$, which could render LDA results unstable, a secondary LDA with only OB-BED and $\mathrm{OB}$ groups was conducted to confirm the reliability of function 2 predictors. Meeting assumption checks (Box's $M p=0.30$ ), the additional analysis yielded a similar solution for the distinction of OB-BED and OB groups, $\chi^{2}(11)=31.64, p<0.001$, with FCTQ $(0.87)$, SSES (0.74), DEBQ (0.70), and SEES (0.69) emerging again as the most important predictors of group differences. Taken together, the LDA findings suggest that $\mathrm{CO}$ can be distinguished from $\mathrm{OB}$, and $\mathrm{OB}-\mathrm{BED}$ groups along a continuum of increasing problematic eating behaviors and attitudes, depression, and childhood adversities, with OB-BED further distinguishable from $\mathrm{OB}$ along a continuum of increasing emotional eating tendencies, and eating-related as well as general self-regulation impairments.
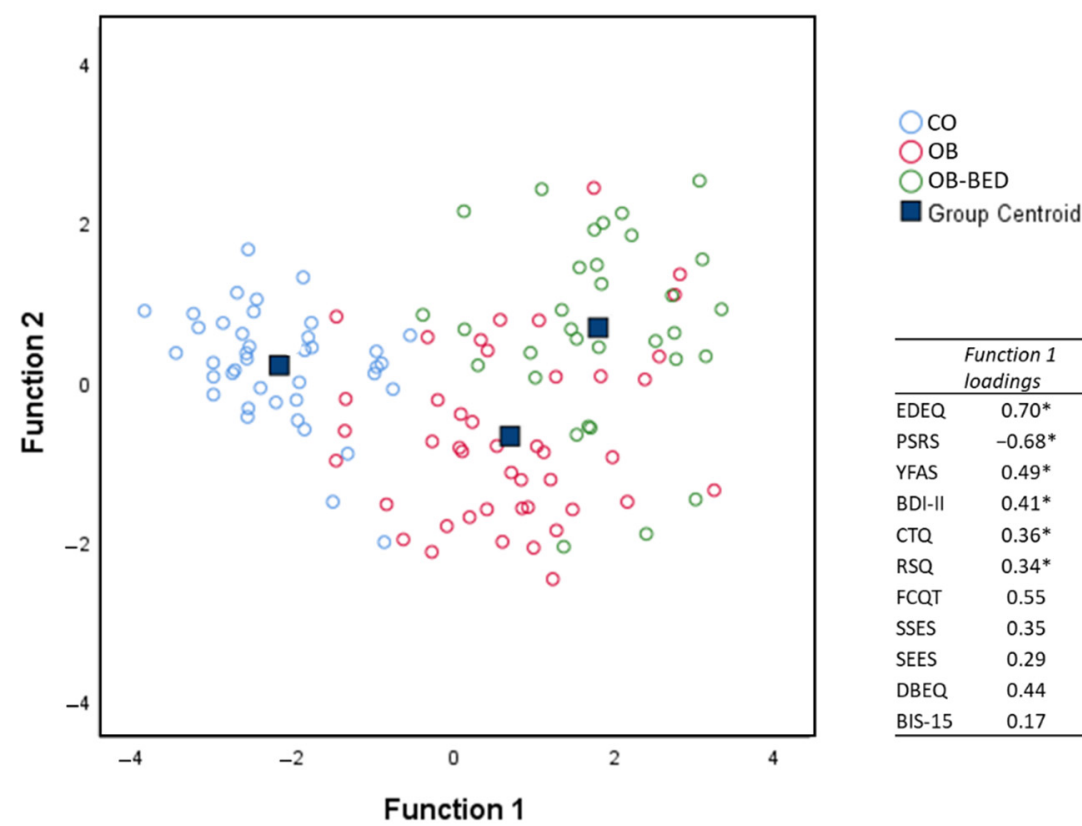

\begin{tabular}{lcc}
\hline & $\begin{array}{c}\text { Function 1 } \\
\text { loadings }\end{array}$ & $\begin{array}{l}\text { Function 2 } \\
\text { loadings }\end{array}$ \\
\hline EDEQ & $0.70^{*}$ & 0.06 \\
PSRS & $-0.68^{*}$ & 0.13 \\
YFAS & $0.49^{*}$ & 0.39 \\
BDI-II & $0.41^{*}$ & 0.21 \\
CTQ & $0.36^{*}$ & 0.05 \\
RSQ & $0.34^{*}$ & 0.21 \\
FCQT & 0.55 & $0.71^{*}$ \\
SSES & 0.35 & $0.64^{*}$ \\
SEES & 0.29 & $0.63^{*}$ \\
DBEQ & 0.44 & $0.45^{*}$ \\
BIS-15 & 0.17 & $0.24^{*}$ \\
\hline
\end{tabular}

Figure 2. Cases and centroids of study groups on the two discriminant functions derived from the linear discriminant analysis (LDA) of questionnaire responses. Asterisks $\left(^{*}\right)$ indicate the largest absolute correlation between each predictor and the discriminant functions. $\mathrm{CO}=\mathrm{control}$; $\mathrm{OB}=$ obese; OB-BED = obese with co-morbid Binge Eating Disorder.

\section{Discussion}

This study aimed to assess differences and commonalities between obese patients with BED and obese individuals without BED. For that, a battery of questionnaires on early life experiences, general psychopathology, and eating-related symptomatology was assessed on the above-mentioned groups and normal-weight controls, whereby the BED group was a clinically diagnosed sample. In almost all questionnaires and subcategories, significant differences could be found between the groups. However, the findings of the LDA showed that $\mathrm{OB}-\mathrm{BED}, \mathrm{OB}$, and $\mathrm{CO}$ can be grouped along a two-dimensional space, with one continuum primarily distinguishing $\mathrm{CO}$ from the $\mathrm{OB}$ and OB-BED groups and a second continuum distinguishing between $\mathrm{OB}$ and $\mathrm{OB}-\mathrm{BED}$ groups. Consistent with previous research, aspects of early life experiences emerged as shared features of $\mathrm{OB}$ and $\mathrm{OB}-$ BED groups, whereas general psychopathology in terms of impulse control impairments distinguished between the groups. However, across both dimensions, features of eatingrelated symptomatology emerged as the most important predictors of commonalities and disparities between obesity with and without BED. These results are discussed in further detail in the following sections. 


\subsection{Eating-Related Symptomatology}

Although not included in the DSM-5 diagnostic criteria [2], strong concerns about shape and weight are core psychopathologies that BED shares with other EDs like anorexia nervosa or bulimia nervosa [23,24]. Significant concerns of shape and weight and elevated measures of eating disturbances also emerge in connection with obesity in large community samples [25]. For example, Hilbert et al. [67] reported an increased risk of 11 to 20 times for obese individuals to show eating disorder psychopathology compared with individuals with normal weight. Consistent with these findings, OB-BED patients scored consistently higher on the EDEQ than OB participants, who scored higher than controls, with the subscale restraint as the only exception (for similar findings, see [68]). The LDA also suggests that the $\mathrm{OB}$ and $\mathrm{OB}-\mathrm{BED}$ groups can be distinguished from controls along a continuum best described by elevated eating disturbances. Although more research on the relative importance of restraint appears warranted (cf. [69]), these findings suggest that shape and weight concerns in obese BED patients should be of special interest since they may be related to the condition's pathogenesis and can determine the therapy outcome [70].

Related to the question of the role of restraint, we assessed the PSRS. This short questionnaire yields the individuals' self-assessment of their own success in dieting, which has been shown to negatively correlate with BMI, rigid dietary control, food cravings, food addiction symptoms, and binge eating, but to correlate positively with flexible dietary control [59]. In our study, the OB-BED and OB groups reported much lower scores in dieting successfully than controls but remained comparable, which was also indicated by the LDA associating the PSRS with the continuum relevant to the distinction of healthy controls from $\mathrm{OB}$ and OB-BED groups. A possible explanation for the lack of distinction between OB-BED and $\mathrm{OB}$ groups according to restraint is that the questionnaire measures the attempt to lose weight, rather than actual restraint eating behavior, which more specifically relates to disordered eating [71,72].

However, OB-BED and $\mathrm{OB}$ groups were clearly distinguishable according to features of emotional eating, as suggested by the LDA and individual analyses. In the SEES, which was developed with the expectation that persons with lower eating pathologies tend to eat rather more when happy, and persons with higher eating pathologies more when having negative emotions [54]; the average score of eating under negative emotions was increased in OB-BED compared with both OB and controls. Controls, instead, reported eating more when feeling happy. The differences between OB-BED and OB were most pronounced for sadness as a low arousal emotion, which is consistent with similar findings for binge eating in patients with bulimia nervosa [73]. These findings may suggest that mechanisms of decreased food uptake while experiencing high arousal in the form of emotions are decoupled in BED with comorbid obesity but not in obesity without BED. This idea is further supported by similar patterns found for stress eating tendencies in the SSES. Again, the OB-BED group showed the highest score by far, while the OB group reported to eat only slightly more. Controls instead reported eating less under stress. These findings are consistent with laboratory studies showing an increased speed of food uptake after stress exposure in BED patients [74].

In line with the above-summarized findings, the DEBQ, which also measures emotional eating on one subscale, was found to distinguish between OB-BED and OB groups. The OB-BED group in our study showed the highest scores in emotional eating in the DEBQ, including the subscales for diffuse emotions [56]. It stands to reason that these differences hint at the role of emotional dysregulation in predicting binge eating behavior [75].

Further lines of distinction between OB-BED and OB groups emerged along with external eating and food craving tendencies. Consistent with previous findings [75-77], OB-BED patients scored higher than both OB and controls on the DEBQ external eating subscale, which measures the tendency to eat after being exposed to food cues. In a similar vein, OB-BED, OB, and controls were found to differ consistently across FCQT's food craving subscales. Although strong food cravings can be found in healthy individuals, too, it has been shown that those with binge eating symptoms score higher in food craving 
assessments [37]. Consistent with our findings, this association is stronger for binge eating than for only obesity [35-37]. Innamorati et al. [78] even developed a potential cut-off score (157.5) of the FCQT for identifying clinical-level binge eating. Although our clinically diagnosed BED sample did not meet this criterion on average (142.3), findings from the LDA, which identified FCQT scores among the most important predictors for distinguishing between OB-BED and OB groups, generally support this contention.

As BED has been linked to high impulsivity and related conditions like substance use disorders [32,79], it has been suggested that BED might share features with food addiction $[41,48]$. Extending this line of research, we compared OB-BED, OB, and controls in terms of food addiction as measured by the YFAS 2.0. In our study, the highest prevalence of $76 \%$ for food addiction was found in the OB-BED group, followed by OB $(40 \%)$ and controls $(0 \%)$. For the OB-BED group, this is a lower prevalence than shown in previous studies $[38,80]$, though it should be mentioned that food addiction prevalence rates are inhomogeneous across different samples [41]. Given the clear difference in food addiction prevalence between OB-BED and OB groups, it might be considered surprising to find that food addiction in the LDA was associated with the more general distinction between healthy and clinical groups, rather than between OB-BED and OB groups. It should be noted, however, that the LDA included scores for food addiction symptoms rather than scores for food addiction severity, rendering these findings only partly comparable. The decision to include food addiction symptoms rather than severity scores in the LDA was mainly due to statistical reasons, as the absence of variance in severity scores of controls (i.e., none of the controls were classified as food addicted) violated the LDAs assumptions.

\subsection{General Psychopathology}

Looking at general psychopathology associated with BED, we investigated the role of impulse control impairments in relation to comorbid obesity using the BIS-15. Impulsivity has been frequently investigated in BED in the past. Experimental studies revealed that patients with BED show higher rash-spontaneous behavior, especially toward food, but also in general [17]. Neurobiological findings also link BED to impulsive/compulsive disorders, based on findings of the corticostriatal circuitry regulation of motivation and impulse control [81]. Likewise, the link between impulsivity and obesity has been of interest. A study gathering data about impulsivity in a large sample of the general population showed an association with obesity [82]. However, research suggests that BED surpasses obesity without BED in terms of impulsivity [17], which is consistent with the present findings. Specifically, OB-BED patients scored overall higher than OB and control participants on the BIS-15, with OB participants exceeding controls only on the subscale of attentional impulsivity. This scoring is in line with the findings of Loeber et al. [83], and further supported by the LDA associating impulsivity scores more strongly with the specific distinction between OB-BED and OB groups.

Further replicating previous findings on the relation between depressive symptoms and BED and obesity $[84,85]$, we found that BDI scores of OB-BED patients exceeded those of $\mathrm{OB}$, which exceeded those of controls. Interestingly, and although previous studies associated high BDI scores and depressed moods specifically with BED [21,22], the LDA suggests a linear transition from healthy controls to $\mathrm{OB}$ and OB-BED groups with increasing levels of depression. However, the effects of depression on BED are likely mediated through their effect on self-regulation impairments [21,86], which our analysis also suggested are more specific for the distinction of obese patients with and without obesity.

\subsection{Early Life Experiences}

Finally, adverse childhood events have been repeatedly linked to both obesity and BED $[9,10]$. It has been argued that adverse experiences may impair coping mechanisms due to mental and emotional perturbations but may also link to metabolic alterations due to stress, and in doing so, promote the development of obesity and BED [11,12]. Consistent with these findings, individual analysis as well as LDA groupings suggest that $\mathrm{OB}$ and 
OB-BED groups can be distinguished from healthy, normal-weight controls on the basis of overall CTQ trauma scores. However, whereas previous research indicated further distinctions between OB-BED and OB groups in terms of traumatic experiences $[11,87]$ these differences were not significant in the present sample. In part, this may have been caused by a smaller sample size of our study or because the sexual and physical abuse scores were slightly higher in the OB group than in the OB-BED group (for similar findings, see [88]). Though further research on more specific contributions may be required, our findings corroborate childhood trauma as a general risk factor for obesity and BED, which should be considered whilst offering treatment.

In a similar vein, attachment styles, formed in early childhood, have been considered in the pathogenesis of $\mathrm{BED}$ and obesity $[14,15]$ and emerged as predicting differences of $\mathrm{OB}$ BED and OB groups towards controls. Specifically, OB-BED patients showed elevated RSQ scores for separation anxiety, closeness anxiety, and lack of trust, whereas OB participants differed from controls only with respect to lack of trust. To our knowledge, this is the first study assessing the RSQ in comparing groups of BED, obesity, and normal-weight controls. The findings could suggest that binge eating in obese individuals might result from poor emotional coping mechanisms [89-91]. However, both individual analysis and the LDA did not identify differences in attachment styles as specifically differentiating between OB-BED and OB groups, suggesting that further research on the role of attachment styles in BED is needed.

\subsection{Limitations}

Of course, interpreting these findings is subject to limitations. First, the current study investigated the psychopathological space between obese individuals with and without BED in a cross-sectional design. Although the evidence largely supports the idea of BED and obesity forming part of a broad spectrum of eating-related behaviors and disorders in terms of childhood adversities and different aspects of general and eating-related psychopathology, the cross-sectional design prevents any exploration of a transition of individuals from one group to another. This gap may be addressed in studies using similar methods but with a longitudinal design. Second, due to the fact that we included both incident (treatment-naive) as well as prevalent (treatment-experienced) patients, we cannot exclude the possibility that prior recommendations and treated aspects of eating disorder-specific pathology could have modified the answers collected in the questionnaires, limiting interpretations as to whether the observed patterns are sensitive to change. Third, and relatedly, it must be noted that control participants were primarily recruited among individuals considering bariatric surgery as an option for weight loss (OB group), hospital staff, and medical students (normal-weight controls). Although participant groups were comparable in terms of sociodemographic features, we cannot exclude that the observed data pattern is sensitive to sample composition differences.

\section{Conclusions}

This study sought to show and reproduce specific characteristics of BED with comorbid obesity, especially in comparison with obesity without BED. Importantly, we only tested clinically diagnosed BED patients and obese individuals without a history of ED to make a clear comparison. The findings underline the distinct psychological and psychopathological features that separate OB-BED from obesity. Although OB-BED and OB groups share problematic eating behaviors and attitudes, depression, and adverse early life experiences, increasing emotional eating tendencies and eating-related and general self-regulation impairments appear to specifically relate to the emergence of BED. These results should be considered in therapy and when screening for BED in obese individuals.

Author Contributions: Conceptualization, G.P.; formal analysis, G.P. and G.H.; data curation, L.M.S.; writing - original draft preparation, L.M.S.; writing—review and editing, G.P., Y.E., and G.H.; supervision, G.P. All authors have read and agreed to the published version of the manuscript. 
Funding: This research received no external funding.

Institutional Review Board Statement: The study was conducted according to the guidelines of the Declaration of Helsinki, and approved by the Ethics Committee of the Friedrich-Alexander-University Erlangen-Nürnberg (approval no.: 267_17B, 4 December 2017).

Informed Consent Statement: Informed consent was obtained from all subjects involved in the study.

Data Availability Statement: The data presented in this study are available on request from the corresponding author.

Acknowledgments: The present work was performed by L.M.S. in fulfillment of the requirements for obtaining the degree "Dr. med.".

Conflicts of Interest: The authors declare no conflict of interest.

\section{Appendix A}

Unstandardized means \pm standard deviations of questionnaire responses are summarized in Table A1.

Table A1. Questionnaire responses raw scores as a function of participant group.

\begin{tabular}{|c|c|c|c|}
\hline Variable & $\mathrm{CO}$ & OB & OB-BED \\
\hline \multicolumn{4}{|l|}{ EDEQ } \\
\hline Total & $0.7 \pm 0.86$ & $2.5 \pm 1.26$ & $3.2 \pm 0.90$ \\
\hline Restraint & $0.8 \pm 1.13$ & $1.8 \pm 1.54$ & $1.8 \pm 1.49$ \\
\hline Eating Concern & $0.2 \pm 0.71$ & $1.5 \pm 1.43$ & $2.5 \pm 1.35$ \\
\hline Weight Concern & $0.7 \pm 1.01$ & $3.1 \pm 1.43$ & $3.9 \pm 1.00$ \\
\hline Shape Concern & $1.1 \pm 1.08$ & $3.6 \pm 1.47$ & $4.4 \pm 0.84$ \\
\hline \multicolumn{4}{|l|}{ SEES } \\
\hline Happiness & $3.0 \pm 0.28$ & $2.7 \pm 0.59$ & $2.7 \pm 0.71$ \\
\hline Sadness & $3.2 \pm 0.60$ & $3.5 \pm 0.68$ & $4.3 \pm 0.42$ \\
\hline Anger & $2.9 \pm 0.59$ & $2.9 \pm 0.88$ & $3.6 \pm 0.81$ \\
\hline Fear & $2.7 \pm 0.70$ & $2.7 \pm 0.81$ & $3.4 \pm 0.88$ \\
\hline \multicolumn{4}{|l|}{ SSES } \\
\hline Total & $2.8 \pm 0.53$ & $3.1 \pm 0.79$ & $3.9 \pm 0.74$ \\
\hline \multicolumn{4}{|l|}{ DEBQ } \\
\hline Restraint & $2.3 \pm 0.91$ & $2.7 \pm 0.79$ & $2.4 \pm 0.65$ \\
\hline External Eating & $2.9 \pm 0.61$ & $3.0 \pm 0.73$ & $3.6 \pm 0.73$ \\
\hline Emo. Eating total & $1.9 \pm 0.69$ & $2.6 \pm 0.98$ & $3.7 \pm 0.74$ \\
\hline Emo. E. Clearly Labelled & $1.8 \pm 0.73$ & $2.5 \pm 1.05$ & $3.6 \pm 0.90$ \\
\hline Emo. E. Diffused & $2.2 \pm 0.78$ & $2.9 \pm 1.16$ & $4.0 \pm 0.78$ \\
\hline \multicolumn{4}{|l|}{ PSRS } \\
\hline Total & $14.8 \pm 3.72$ & $7.8 \pm 2.99$ & $6.1 \pm 3.07$ \\
\hline \multicolumn{4}{|l|}{ FCQT } \\
\hline Total & $68.9 \pm 18.81$ & $97.2 \pm 37.58$ & $142.3 \pm 30.03$ \\
\hline Cues & $10.2 \pm 3.29$ & $11.4 \pm 3.64$ & $15.8 \pm 3.92$ \\
\hline Hunger & $8.8 \pm 2.92$ & $11.1 \pm 4.29$ & $14.4 \pm 4.10$ \\
\hline Emotions & $6.5 \pm 3.00$ & $10.6 \pm 5.24$ & $16.1 \pm 4.47$ \\
\hline Intentions/Lack of Control & $15.1 \pm 5.41$ & $22.8 \pm 10.04$ & $34.3 \pm 8.57$ \\
\hline Reinforcement & $15.0 \pm 5.43$ & $19.2 \pm 8.88$ & $28.6 \pm 7.71$ \\
\hline Thoughts/Guilt & $13.3 \pm 4.91$ & $22.1 \pm 11.17$ & $33.1 \pm 9.71$ \\
\hline \multicolumn{4}{|l|}{ YFAS } \\
\hline $\begin{array}{r}\text { No. of Symptoms } \\
\text { Severity, } n\end{array}$ & $0.1 \pm 0.78$ & $3.1 \pm 3.15$ & $5.8 \pm 3.35$ \\
\hline None & 44 & 32 & 10 \\
\hline Mild & 0 & 3 & 3 \\
\hline Moderate & 0 & 2 & 5 \\
\hline Severe & 0 & 12 & 19 \\
\hline
\end{tabular}


Table A1. Cont.

\begin{tabular}{|c|c|c|c|}
\hline Variable & $\mathrm{CO}$ & OB & OB-BED \\
\hline \multicolumn{4}{|l|}{ BIS } \\
\hline Total & $29.3 \pm 6.40$ & $31.9 \pm 6.34$ & $34.4 \pm 6.42$ \\
\hline Nonplanning & $10.8 \pm 3.40$ & $10.6 \pm 3.20$ & $11.8 \pm 2.84$ \\
\hline Motoric & $10.1 \pm 2.44$ & $11.3 \pm 2.64$ & $11.1 \pm 3.14$ \\
\hline Attentional & $8.5 \pm 2.45$ & $10.0 \pm 2.96$ & $11.5 \pm 3.13$ \\
\hline \multicolumn{4}{|l|}{ BDI } \\
\hline Total & $6.2 \pm 7.61$ & $14.7 \pm 9.67$ & $19.7 \pm 9.30$ \\
\hline \multicolumn{4}{|l|}{ CTQ } \\
\hline Total & $31.9 \pm 6.16$ & $45.2 \pm 16.76$ & $50.2 \pm 15.75$ \\
\hline Emotional Abuse & $7.2 \pm 2.62$ & $11.1 \pm 5.58$ & $12.9 \pm 5.60$ \\
\hline Physical Abuse & $5.3 \pm 0.78$ & $7.1 \pm 3.54$ & $6.9 \pm 3.32$ \\
\hline Sexual Abuse & $5.0 \pm 0.15$ & $7.0 \pm 4.83$ & $6.8 \pm 3.47$ \\
\hline Emotional Neglect & $8.3 \pm 3.02$ & $12.2 \pm 5.24$ & $14.6 \pm 5.32$ \\
\hline Physical Neglect & $6.1 \pm 1.83$ & $7.8 \pm 3.03$ & $8.9 \pm 3.32$ \\
\hline Denial & $0.6 \pm 0.99$ & $0.5 \pm 0.91$ & $0.2 \pm 0.48$ \\
\hline \multicolumn{4}{|l|}{ RSQ } \\
\hline Fear Separation & $2.5 \pm 0.69$ & $2.6 \pm 0.79$ & $3.0 \pm 0.65$ \\
\hline Fear Intimacy & $2.2 \pm 0.65$ & $2.5 \pm 0.76$ & $2.8 \pm 0.94$ \\
\hline Lack Trust & $2.0 \pm 0.74$ & $2.7 \pm 0.85$ & $3.2 \pm 0.77$ \\
\hline Wish Independence & $3.8 \pm 0.75$ & $4.1 \pm 0.67$ & $4.0 \pm 0.70$ \\
\hline
\end{tabular}

$\overline{\mathrm{CO}}=$ control; $\mathrm{OB}$ = obese; OB-BED = obese with co-morbid Binge Eating Disorder; EDEQ = Eating Disorder Examination-Questionnaire; SEES = Salzburger Emotional Eating Scale; SSES = Salzburger Stress Eating Scale; DEBQ = Dutch Eating Behavior Questionnaire; PSRS = Perceived Self-Regulatory Success in Dieting; FCQT $=$ Food Craving Questionnaire-Trait; YFAS = Yale Food Addiction Scale; BIS = Barratt Impulsiveness Scale - Short Version; BDI = Beck Depression Inventory; CTQ = Childhood Trauma Questionnaire; RSQ = Relationship Scales Questionnaire. Values report mean \pm standard deviation.

\section{References}

1. Qian, J.; Wu, Y.; Liu, F.; Zhu, Y.; Jin, H.; Zhang, H.; Wan, Y.; Li, C.; Yu, D. An update on the prevalence of eating disorders in the general population: A systematic review and meta-analysis. Eat. Weight Disord. 2021. [CrossRef]

2. American Psychiatric Association Diagnostic and Statistical Manual of Mental Disorders; American Psychiatric Association: Washington, DC, USA, 2013; ISBN 0-89042-555-8.

3. McCuen-Wurst, C.; Ruggieri, M.; Allison, K.C. Disordered eating and obesity: Associations between binge-eating disorder, night-eating syndrome, and weight-related comorbidities. Ann. N. Y. Acad. Sci. 2018, 1411, 96-105. [CrossRef]

4. World Health Organization. Country Profiles on Nutrition, Physical Activity and Obesity in the 53 WHO European Region Member States. Methodology and Summary; WHO Regional Office for Europe: Copenhagen, Denmark, 2013.

5. $\quad$ Kessler, R.C.; Berglund, P.A.; Chiu, W.T.; Deitz, A.C.; Hudson, J.I.; Shahly, V.; Aguilar-Gaxiola, S.; Alonso, J.; Angermeyer, M.C.; Benjet, C.; et al. The prevalence and correlates of binge eating disorder in the World Health Organization World Mental Health Surveys. Biol. Psychiatr. 2013, 73, 904-914. [CrossRef]

6. Flegal, K.M.; Kit, B.K.; Orpana, H.; Graubard, B.I. Association of all-cause mortality with overweight and obesity using standard body mass index categories: A systematic review and meta-analysis. JAMA 2013, 309, 71-82. [CrossRef]

7. Chu, D.-T.; Minh Nguyet, N.T.; Nga, V.T.; Thai Lien, N.V.; Vo, D.D.; Lien, N.; Nhu Ngoc, V.T.; Son, L.H.; Le, D.-H.; Nga, V.B.; et al. An update on obesity: Mental consequences and psychological interventions. Diabetes Metab. Syndr. Clin. Res. Rev. 2019, 13, 155-160. [CrossRef]

8. Villarejo, C.; Fernández-Aranda, F.; Jiménez-Murcia, S.; Peñas-Lledó, E.; Granero, R.; Penelo, E.; Tinahones, F.J.; Sancho, C.; Vilarrasa, N.; Montserrat-Gil De Bernabé, M.; et al. Lifetime obesity in patients with eating disorders: Increasing prevalence, clinical and personality correlates. Eur. Eat. Disord. Rev. 2012, 20, 250-254. [CrossRef] [PubMed]

9. Palmisano, G.L.; Innamorati, M.; Vanderlinden, J. Life adverse experiences in relation with obesity and binge eating disorder: A systematic review. J. Behav. Addict. 2016, 5, 11-31. [CrossRef] [PubMed]

10. Caslini, M.; Bartoli, F.; Crocamo, C.; Dakanalis, A.; Clerici, M.; Carrà, G. Disentangling the association between child abuse and eating disorders: A systematic review and meta-analysis. Psychosom. Med. 2016, 78, 79-90. [CrossRef]

11. Amianto, F.; Spalatro, A.V.; Rainis, M.; Andriulli, C.; Lavagnino, L.; Abbate-Daga, G.; Fassino, S. Childhood emotional abuse and neglect in obese patients with and without binge eating disorder: Personality and psychopathology correlates in adulthood. Psychiatr. Res. 2018, 269, 692-699. [CrossRef]

12. Ehlert, U. Enduring psychobiological effects of childhood adversity. Psychoneuroendocrinology 2013, 38, 1850-1857. [CrossRef] [PubMed] 
13. Faber, A.; Dubé, L.; Knäuper, B. Attachment and eating: A meta-analytic review of the relevance of attachment for unhealthy and healthy eating behaviors in the general population. Appetite 2018, 123, 410-438. [CrossRef] [PubMed]

14. Tasca, G.A.; Balfour, L. Attachment and eating disorders: A review of current research. Int. J. Eat. Disord. 2014, 47, 710-717. [CrossRef]

15. Maras, D.; Obeid, N.; Flament, M.; Buchholz, A.; Henderson, K.A.; Gick, M.; Goldfield, G.S. Attachment Style and Obesity: Disordered Eating Behaviors as a Mediator in a Community Sample of Canadian Youth. J. Dev. Behav. Pediatr. 2016, 37, 762-770. [CrossRef] [PubMed]

16. Yohn, S.E.; Galbraith, J.; Calipari, E.S.; Conn, P.J. Shared Behavioral and Neurocircuitry Disruptions in Drug Addiction, Obesity, and Binge Eating Disorder: Focus on Group I mGluRs in the Mesolimbic Dopamine Pathway. ACS Chem. Neurosci. 2019, 10, 2125-2143. [CrossRef]

17. Giel, K.E.; Teufel, M.; Junne, F.; Zipfel, S.; Schag, K. Food-related impulsivity in obesity and binge eating disorder-A systematic update of the evidence. Nutrients 2017, 9, 1170. [CrossRef]

18. Paslakis, G.; Kühn, S.; Grunert, S.; Erim, Y. Explicit and Implicit Approach vs. Avoidance Tendencies towards High vs. Low Calorie Food Cues in Patients with Obesity and Active Binge Eating Disorder. Nutrients 2017, 9, 1068. [CrossRef]

19. Hege, M.A.; Stingl, K.T.; Kullmann, S.; Schag, K.; Giel, K.E.; Zipfel, S.; Preissl, H. Attentional impulsivity in binge eating disorder modulates response inhibition performance and frontal brain networks. Int. J. Obes. 2015, 39, 353-360. [CrossRef]

20. Hernandez, D.; Mehta, N.; Geliebter, A. Meal-Related Acyl and Des-Acyl Ghrelin and Other Appetite-Related Hormones in People with Obesity and Binge Eating. Obesity 2019, 27, 629-635. [CrossRef]

21. Schulz, S.; Laessle, R.G. Associations of negative affect and eating behaviour in obese women with and without binge eating disorder. Eat. Weight Disord. 2010, 15, e287-e293. [CrossRef] [PubMed]

22. Krehbiel, J.; Halbeisen, G.; Kühn, S.; Erim, Y.; Paslakis, G. Too hot to handle: Mood states moderate implicit approach vs. avoidance tendencies toward food cues in patients with obesity and active binge eating disorder. J. Psychiatr. Res. 2021, 143, 302-308. [CrossRef] [PubMed]

23. Wang, S.B.; Jones, P.J.; Dreier, M.; Elliott, H.; Grilo, C.M. Core psychopathology of treatment-seeking patients with binge-eating disorder: A network analysis investigation. Psychol. Med. 2019, 49, 1923-1928. [CrossRef]

24. Lewer, M.; Bauer, A.; Hartmann, A.; Vocks, S. Different Facets of Body Image Disturbance in Binge Eating Disorder: A Review. Nutrients 2017, 9, 1294. [CrossRef] [PubMed]

25. Rø, Ø.; Reas, D.L.; Rosenvinge, J. The impact of age and BMI on Eating Disorder Examination Questionnaire (EDE-Q) scores in a community sample. Eat. Behav. 2012, 13, 158-161. [CrossRef] [PubMed]

26. Wiedemann, A.A.; Ivezaj, V.; Barnes, R.D. Characterizing emotional overeating among patients with and without binge-eating disorder in primary care. Gen. Hosp. Psychiatr. 2018, 55, 38-43. [CrossRef] [PubMed]

27. Zeeck, A.; Stelzer, N.; Linster, H.W.; Joos, A.; Hartmann, A. Emotion and eating in binge eating disorder and obesity. Eur. Eat. Disord. Rev. 2010, 19, 426-437. [CrossRef]

28. Ricca, V.; Castellini, G.; Lo Sauro, C.; Ravaldi, C.; Lapi, F.; Mannucci, E.; Rotella, C.M.; Faravelli, C. Correlations between binge eating and emotional eating in a sample of overweight subjects. Appetite 2009, 53, 418-421. [CrossRef] [PubMed]

29. Davis, C.; Levitan, R.D.; Carter, J.; Kaplan, A.S.; Reid, C.; Curtis, C.; Patte, K.; Kennedy, J.L. Personality and eating behaviors: A case-control study of binge eating disorder. Int. J. Eat. Disord. 2008, 41, 243-250. [CrossRef]

30. Pinaquy, S.; Chabrol, H.; Simon, C.; Louvet, J.P.; Barbe, P. Emotional eating, alexithymia, and binge-eating disorder in obese women. Obes. Res. 2003, 11, 195-201. [CrossRef]

31. Meule, A.; Reichenberger, J.; Blechert, J. Development and preliminary validation of the Salzburg Stress Eating Scale. Appetite 2018, 120, 442-448. [CrossRef] [PubMed]

32. Agüera, Z.; Lozano-Madrid, M.; Mallorquí-Bagué, N.; Jiménez-Murcia, S.; Menchón, J.M.; Fernández-Aranda, F. A review of binge eating disorder and obesity. Neuropsychiatrie 2021, 35, 57-67. [CrossRef]

33. Johnson, F.; Pratt, M.; Wardle, J. Dietary restraint and self-regulation in eating behavior. Int. J. Obes. 2012, 36, 665-674. [CrossRef]

34. Spoor, S.T.P.; Stice, E.; Bekker, M.H.J.; Van Strien, T.; Croon, M.A.; Van Heck, G.L. Relations between dietary restraint, depressive symptoms, and binge eating: A longitudinal study. Int. J. Eat. Disord. 2006, 39, 700-707. [CrossRef] [PubMed]

35. Meule, A.; Lutz, A.; Vögele, C.; Kübler, A. Food cravings discriminate differentially between successful and unsuccessful dieters and non-dieters. Validation of the Food Cravings Questionnaires in German. Appetite 2012, 58, 88-97. [CrossRef]

36. Meule, A. Twenty Years of the Food Cravings Questionnaires: A Comprehensive Review. Curr. Addict. Rep. 2020, 7, 30-43. [CrossRef]

37. Van den Eynde, F.; Koskina, A.; Syrad, H.; Guillaume, S.; Broadbent, H.; Campbell, I.C.; Schmidt, U. State and trait food craving in people with bulimic eating disorders. Eat. Behav. 2012, 13, 414-417. [CrossRef]

38. Carter, J.C.; Van Wijk, M.; Rowsell, M. Symptoms of 'food addiction' in binge eating disorder using the Yale Food Addiction Scale version 2.0. Appetite 2019, 133, 362-369. [CrossRef]

39. Davis, C.; Curtis, C.; Levitan, R.D.; Carter, J.C.; Kaplan, A.S.; Kennedy, J.L. Evidence that "food addiction" is a valid phenotype of obesity. Appetite 2011, 57, 711-717. [CrossRef]

40. Davis, C. Compulsive Overeating as an Addictive Behavior: Overlap between Food Addiction and Binge Eating Disorder. Curr. Obes. Rep. 2013, 2, 171-178. [CrossRef] 
41. Penzenstadler, L.; Soares, C.; Karila, L.; Khazaal, Y. Systematic Review of Food Addiction as Measured with the Yale Food Addiction Scale: Implications for the Food Addiction Construct. Curr. Neuropharmacol. 2018, 17, 526-538. [CrossRef]

42. Hession, M.; Rolland, C.; Kulkarni, U.; Wise, A.; Broom, J. Systematic review of randomized controlled trials of low-carbohydrate vs. low-fat/low-calorie diets in the management of obesity and its comorbidities. Obes. Rev. 2009, 10, 36-50. [CrossRef]

43. Brownley, K.A.; Berkman, N.D.; Peat, C.M.; Lohr, K.N.; Cullen, K.E.; Bann, C.M.; Bulik, C.M. Binge-Eating Disorder in Adults: A Systematic Review and Meta-analysis. Ann. Intern. Med. 2016, 165, 409-420. [CrossRef]

44. White, M.A.; Kalarchian, M.A.; Masheb, R.M.; Marcus, M.D.; Grilo, C.M. Loss of control over eating predicts outcomes in bariatric surgery patients: A prospective, 24-month follow-up study. J. Clin. Psychiatr. 2010, 71, 175-184. [CrossRef]

45. Hilbert, A.; Petroff, D.; Herpertz, S.; Pietrowsky, R.; Tuschen-Caffier, B.; Vocks, S.; Schmidt, R. Meta-Analysis of the Efficacy of Psychological and Medical Treatments for Binge-Eating Disorder. J. Consult. Clin. Psychol. 2019, 87, 91-105. [CrossRef] [PubMed]

46. Grilo, C.M. Psychological and Behavioral Treatments for Binge-Eating Disorder. J. Clin. Psychiatr. 2017, 78 (Suppl. S1), $20-24$. [CrossRef]

47. Escandón-Nagel, N.; Peró, M.; Grau, A.; Soriano, J.; Feixas, G. Alimentación emocional y conflictos cognitivos como predictores del trastorno por atracón en pacientes con obesidad. Int. J. Clin. Health Psychol. 2018, 18, 52-59. [CrossRef]

48. Gearhardt, A.; White, M.; Potenza, M. Binge eating disorder and food addiction. Curr. Drug Abuse Rev. 2011, 4, 201-207. [CrossRef] [PubMed]

49. Meule, A. German Version of the Eating Disorder Diagnostic Scale-DSM-5 Version 2015. Available online: https://adrianmeule. files.wordpress.com/2013/05/eddsgerman.pdf (accessed on 10 October 2021).

50. Faul, F.; Erdfelder, E.; Lang, A.G.; Buchner, A. G*Power 3: A flexible statistical power analysis program for the social, behavioral, and biomedical sciences. Behav. Res. Methods 2007, 39, 175-191. [CrossRef] [PubMed]

51. Fairburn, C.G.; Beglin, S.J. Assessment of eating disorders: Interview or self-report questionnaire? Int. J. Eat. Disord. 1994, 16, 363-370. [PubMed]

52. Fairburn, C.G.; Cooper, Z. The eating disorder examination. In Binge Eating: Nature, Assessment and Treatment; Fairburn, C.G., Wilson, G.T., Eds.; Guilford Press: New York, NY, USA, 1993; pp. 317-360.

53. Hilbert, A.; Tuschen-Caffier, B. Eating Disorder Examination-Questionnaire: Deutschsprachige Übersetzung; Münster Verlag Psychotherapie: Münster, Germany, 2006.

54. Meule, A.; Reichenberger, J.; Blechert, J. Development and Preliminary Validation of the Salzburg Emotional Eating Scale. Front. Psychol. 2018, 9, 88. [CrossRef]

55. Reichenberger, J.; Pannicke, B.; Arend, A.K.; Petrowski, K.; Blechert, J. Does stress eat away at you or make you eat? EMA measures of stress predict day to day food craving and perceived food intake as a function of trait stress-eating. Psychol. Health 2021, 36, 129-147. [CrossRef]

56. van Strien, T.; Frijters, J.E.R.; Bergers, G.P.A.; Defares, P.B. The Dutch Eating Behavior Questionnaire (DEBQ) for assessment of restrained, emotional, and external eating behavior. Int. J. Eat. Disord. 1986, 5, 295-315. [CrossRef]

57. Nagl, M.; Hilbert, A.; de Zwaan, M.; Braehler, E.; Kersting, A. The German Version of the Dutch Eating Behavior Questionnaire: Psychometric Properties, Measurement Invariance, and Population-Based Norms. PLoS ONE 2016, 11, e0162510. [CrossRef] [PubMed]

58. Fishbach, A.; Friedman, R.S.; Kruglanski, A.W. Leading us not unto temptation: Momentary allurements elicit overriding goal activation. J. Pers. Soc. Psychol. 2003, 84, 296-309. [CrossRef]

59. Meule, A.; Papies, E.K.; Kübler, A. Differentiating between successful and unsuccessful dieters. Validity and reliability of the Perceived Self-Regulatory Success in Dieting Scale. Appetite 2012, 58, 822-826. [CrossRef] [PubMed]

60. Cepeda-Benito, A.; Gleaves, D.; Williams, T.; Erath, S. The development and validation of the State and Trait Food-Cravings Questionnaire. Behav. Ther. 2000, 31, 151-173. [CrossRef]

61. Gearhardt, A.N.; Corbin, W.R.; Brownell, K.D. Development of the Yale Food Addiction Scale Version 2.0. Psychol. Addict. Behav. J. Soc. Psychol. Addict. Behav. 2016, 30, 113-121. [CrossRef] [PubMed]

62. Meule, A.; Müller, A.; Gearhardt, A.N.; Blechert, J. German version of the Yale Food Addiction Scale 2.0: Prevalence and correlates of "food addiction" in students and obese individuals. Appetite 2017, 115, 54-61. [CrossRef] [PubMed]

63. Meule, A.; Vögele, C.; Kübler, A. Psychometric evaluation of the German Barratt Impulsiveness Scale-Short Version (BIS-15). Diagnostica 2011, 57, 126-133. [CrossRef]

64. Hautzinger, M.; Keller, F.; Kühner, C. BDI-II. Beck-Depressions-Inventar, 2nd ed.; Pearson: London, UK, 2009.

65. Bader, K.; Hänny, C.; Schäfer, V.; Neuckel, A.; Kuhl, C. Childhood Trauma Questionnaire-Psychometrische Eigenschaften einer deutschsprachigen Version. [Childhood Trauma Questionnaire-Psychometric properties of a German version]. Z. Klin. Psychol. Psychother. 2009, 38, 223-230. [CrossRef]

66. Steffanowski, A.; Oppl, M.; Meyerberg, J.; Juergen, S.; Wittmann, W.; Nübling, R. Psychometrische Überprüfung einer Deutschsprachigen Version des Relationship Scales Questionaire (RSQ); Psychosozial: Giessen, Germany, 2001; pp. 320-342. ISBN 3-89806-081-0.

67. Hilbert, A.; de Zwaan, M.; Braehler, E. How Frequent Are Eating Disturbances in the Population? Norms of the Eating Disorder Examination-Questionnaire. PLoS ONE 2012, 7, e29125. [CrossRef]

68. Özdin, S.; Karabekiroğlu, A.; Özbalcı, G.S.; Aker, A.A. The effect of cognitive symptoms in binge eating disorder on depression and self-esteem: A cross-sectional study. Eat. Weight Disord. 2021, 26, 1483-1489. [CrossRef] [PubMed] 
69. Çalışır, S.; Çalışır, A.; Arslan, M.; İnanlı, İ.; Çalışkan, A.M.; Eren, İ. Assessment of depressive symptoms, self-esteem, and eating psychopathology after laparoscopic sleeve gastrectomy: 1-year follow-up and comparison with healthy controls. Eat. Weight Disord. 2020, 25, 1515-1523. [CrossRef]

70. Grilo, C.M.; White, M.A.; Gueorguieva, R.; Wilson, G.T.; Masheb, R.M. Predictive significance of the overvaluation of shape/weight in obese patients with binge eating disorder: Findings from a randomized controlled trial with 12-month follow-up. Psychol. Med. 2013, 43, 1335-1344. [CrossRef] [PubMed]

71. Gagnon-Girouard, M.P.; Bégin, C.; Provencher, V.; Tremblay, A.; Boivin, S.; Lemieux, S. Can we apply the dual-pathway model of overeating to a population of weight-preoccupied overweight women? Int. J. Eat. Disord. 2009, 42, 244-252. [CrossRef]

72. Zambrowicz, R.; Schebendach, J.; Sysko, R.; Mayer, L.E.S.; Walsh, B.T.; Steinglass, J.E. Relationship between three factor eating questionnaire-restraint subscale and food intake. Int. J. Eat. Disord. 2019, 52, 255-260. [CrossRef] [PubMed]

73. Meule, A.; Richard, A.; Schnepper, R.; Reichenberger, J.; Georgii, C.; Naab, S.; Voderholzer, U.; Blechert, J. Emotion regulation and emotional eating in anorexia nervosa and bulimia nervosa. Eat. Disord. 2021, 29, 175-191. [CrossRef]

74. Schulz, S.; Laessle, R.G. Stress-induced laboratory eating behavior in obese women with binge eating disorder. Appetite 2012, 58, 457-461. [CrossRef]

75. Benzerouk, F.; Djerada, Z.; Bertin, E.; Barrière, S.; Gierski, F.; Kaladjian, A. Contributions of emotional overload, emotion dysregulation, and impulsivity to eating patterns in obese patients with binge eating disorder and seeking bariatric surgery. Nutrients 2020, 12, 3099. [CrossRef]

76. Mason, T.B.; Lewis, R.J. Profiles of Binge Eating: The Interaction of Depressive Symptoms, Eating Styles, and Body Mass Index. Eat. Disord. 2014, 22, 450-460. [CrossRef]

77. Ferrer-Garcia, M.; Pla-Sanjuanelo, J.; Dakanalis, A.; Vilalta-Abella, F.; Riva, G.; Fernandez-Aranda, F.; Sánchez, I.; Ribas-Sabaté, J.; Andreu-Gracia, A.; Escandón-Nagel, N.; et al. Eating behavior style predicts craving and anxiety experienced in food-related virtual environments by patients with eating disorders and healthy controls. Appetite 2017, 117, 284-293. [CrossRef]

78. Innamorati, M.; Imperatori, C.; Balsamo, M.; Tamburello, S.; Belvederi Murri, M.; Contardi, A.; Tamburello, A.; Fabbricatore, M. Food cravings questionnaire-trait (FCQ-T) discriminates between obese and overweight patients with and without binge eating tendencies: The italian version of the FCQ-T. J. Pers. Assess. 2014, 96, 632-639. [CrossRef] [PubMed]

79. Grilo, C.M.; White, M.A.; Barnes, R.D.; Masheb, R.M. Psychiatric disorder co-morbidity and correlates in an ethnically diverse sample of obese patients with binge eating disorder in primary care settings. Compr. Psychiatr. 2013, 54, 209-216. [CrossRef] [PubMed]

80. Fauconnier, M.; Rousselet, M.; Brunault, P.; Thiabaud, E.; Lambert, S.; Rocher, B.; Challet-Bouju, G.; Grall-Bronnec, M. Food addiction among female patients seeking treatment for an eating disorder: Prevalence and associated factors. Nutrients 2020, 12, 1897. [CrossRef]

81. Kessler, R.M.; Hutson, P.H.; Herman, B.K.; Potenza, M.N. The neurobiological basis of binge-eating disorder. Neurosci. Biobehav. Rev. 2016, 63, 223-238. [CrossRef]

82. Bénard, M.; Camilleri, G.; Etilé, F.; Méjean, C.; Bellisle, F.; Reach, G.; Hercberg, S.; Péneau, S. Association between Impulsivity and Weight Status in a General Population. Nutrients 2017, 9, 217. [CrossRef]

83. Loeber, S.; Rustemeier, M.; Paslakis, G.; Pietrowsky, R.; Müller, A.; Herpertz, S. Mood and restrained eating moderate foodassociated response inhibition in obese individuals with binge eating disorder. Psychiatr. Res. 2018, 264, 346-353. [CrossRef]

84. Smith, C.E.; Hawkins, M.A.W.; Williams-Kerver, G.A.; Duncan, J. Depression subtypes, binge eating, and weight loss in bariatric surgery candidates. Surg. Obes. Relat. Dis. 2020, 16, 690-697. [CrossRef] [PubMed]

85. Udo, T.; McKee, S.A.; Grilo, C.M. Factor structure and clinical utility of the Beck Depression Inventory in patients with binge eating disorder and obesity. Gen. Hosp. Psychiatr. 2015, 37, 120-125. [CrossRef]

86. Meule, A.; Blechert, J. Interactive and indirect effects of trait impulsivity facets on body mass index. Appetite 2017, 118, 60-65. [CrossRef]

87. Belli, H.; Ural, C.; Akbudak, M.; Sagaltıc1, E. Levels of childhood traumatic experiences and dissociative symptoms in extremely obese patients with and without binge eating disorder. Nord. J. Psychiatr. 2019, 73, 527-531. [CrossRef]

88. Palmisano, G.L.; Innamorati, M.; Sarracino, D.; Bosco, A.; Pergola, F.; Scaltrito, D.; Giorgio, B.; Vanderlinden, J. Trauma and dissociation in obese patients with and without binge eating disorder: A case-control study. Cogent Psychol. 2018, 5, 1-20. [CrossRef]

89. Han, S.; Carole Pistole, M. College student binge eating: Insecure attachment and emotion regulation. J. Coll. Stud. Dev. 2014, 55, 16-29. [CrossRef]

90. Shakory, S.; Van Exan, J.; Mills, J.S.; Sockalingam, S.; Keating, L.; Taube-Schiff, M. Binge eating in bariatric surgery candidates: The role of insecure attachment and emotion regulation. Appetite 2015, 91, 69-75. [CrossRef]

91. Blomquist, K.K.; Ansell, E.B.; White, M.A.; Masheb, R.M.; Grilo, C.M. Interpersonal problems and developmental trajectories of binge eating disorder. Compr. Psychiatr. 2012, 53, 1088-1095. [CrossRef] [PubMed] 